Doi: $\underline{\text { dx.doi.org/10.17921/2525-5320.2016.215-224 }}$

\title{
GESTÃO DE SALA DE AULA: A INDISCIPLINA SOB A PERSPECTIVA DOS
}

ALUNOS

Célia Andréia Sant' Anna* - UNOPAR

Fábio Luiz da Silva* - UNOPAR

Palavras-chave: Professores. Indisciplina Escolar. Gestão de Sala de Aula. Alunos.

\section{INTRODUÇÃO}

A indisciplina escolar constitui atualmente um dos maiores desafios aos educadores, sendo constantemente tema de discussões entre os profissionais e motivo de estresse nas relações interpessoais. Alguns atribuem a indisciplina na escola a falta de "domínio do conteúdo", por parte do professor, outros ao desinteresse dos educandos nos conteúdos integrantes da matriz curricular, entretanto, Walters e Frei (2009) atribuem tal comportamento a falta de gestão de sala de aula.

É preciso ressaltar que na maioria das vezes a indisciplina é ocasional, ou seja, a mesma turma que é extremamente difícil para um professor pode não trazer transtornos a outro. A partir desta observação tivemos a clareza de que a forma que o educador gere suas aulas é refletida no comportamento de seus educandos. Marshall (2003), afirma que a "gestão de sala de aula trata de como se desenvolvem as atividades; a disciplina trata de como as pessoas se comportam [...]". Assim, quando não se estabelecem rotinas (gestão), é preciso disciplinar.

A partir de diversos questionamentos e tendo em vista a escassa bibliografia nacional a respeito de tal assunto, optou-se por realizar uma pesquisa constituída por questionário e entrevistas aos alunos do ensino fundamental de uma escola da área central da cidade de Londrina, Paraná. Este artigo pretende provocar uma reflexão sobre a indisciplina na escola na perspectiva dos alunos e utilizando como base o livro Gestão do Comportamento e a Disciplina em Sala de Aula, apontando possíveis instrumentos e atitudes que possam contribuir para debate científico sobre indisciplina escolar, fornecendo elementos aos educadores para ampliarem as percepções com

\footnotetext{
* E-mail: cesantana77@hotmail.com

* E-mail: fabio.luiz@kroton.com.br
} 
relação este tema.

\section{DESENVOLVIMENTO}

\section{Gestão de sala de aula $x$ indisciplina}

As escolas frequentemente têm dificuldades em estabelecer e efetivar normas disciplinares. Esta talvez seja a causa da dedicação de quase metade do tempo de aula a atividades não relacionadas ao aprendizado, assim, faz-se necessária a otimização deste tempo escolar para que os alunos ocupem-se mais com atividades didáticas, o que consequentemente aumentaria o aprendizado do educando.

Já o ensino nas escolas brasileiras vem passando por diversas transformações desde sua implantação. Inicialmente pretendia-se atender apenas as classes mais abastadas, depois de um longo tempo a massificação da escola pública trouxe consigo novas demandas e alunos com os mais diversos históricos, o que trouxe à tona as deficiências de um modelo de escola desatualizado e deficitário.

Sendo a disciplina em sala de aula um importante fator na qualidade da aprendizagem, faz-se necessário estabelecer estratégias não apenas para engajar os alunos nos conteúdos trabalhados, mas também gerir a sala de aula de forma o comportamento dos alunos esteja dentro das normas pré-estabelecidas, para que o processo ensino-aprendizagem realmente ocorra. Este trabalho, porém, não é dever apenas do docente, cabendo aos gestores, pais de alunos e até os próprios alunos a manutenção de um ambiente disciplinado e ainda, o sucesso desta gestão envolve também outros espaços escolares, abrangendo por exemplo, o ônibus, banheiros, pátio e etc.

Segundo Walters e Frei, 2009, "Professores que tem problemas para estabelecer a gestão e a ordem em sala de aula têm um moral de derrotados e não se julgam à altura da tarefa, o que resulta em estresse e desgaste" (Pág. 19). Esse estresse costuma afetar seu estado emocional, sua saúde e algumas vezes até outras pessoas (alunos, colegas e familiares). Gerir a sala de aula diz respeito à organização geral das atividades e como ela funciona, enquanto o controle da disciplina é a gestão específica do comportamento estudantil:

Para falar diretamente, os professores eficientes gerem a classe por meio de procedimentos e rotinas. Esse processo muitas vezes se ocupa de várias questões vinculadas com a disciplina em sala de aula. Em contrapartida, os professores ineficientes apenas tentam disciplinar seus alunos com ameaças e punições em vez de estabelecer um alicerce para o ambiente de 
Walters e Frei afirmam também que, se a ordem não é estabelecida previamente por uma gestão eficaz é provável que a aprendizagem também não seja efetiva. Pode parecer redundante mas, os educandos precisam saber exatamente o que o docente espera deles, como deseja que procedam e como quer que se comportem. Para isso, é fundamental que as normas sejam estabelecidas em conjunto desde o primeiro dia de aula, podendo ser anotadas em um cartaz que ficará em um lugar visível a todos, para que, caso alguma regra seja descumprida ao longo do ano o professor possa se voltar a ela juntamente com a turma para refletir a respeito. É essencial também que ao apresentar suas expectativas em relação aos alunos, estas sejam positivas pois, "[...] pesquisas mostram que tudo que o mestre espera é geralmente aquilo que os discípulos tendem a produzir" (WONG; WONG, 1998).

O professor não aprende apenas com a experiência, é necessária também a reflexão, questionando as metas e valores que norteiam seu trabalho, reconhecendo as diferenças entre suas práticas e as dos profissionais bem sucedidos, pois basearse apenas no contexto o qual atua ou em seus pressupostos torna sua reflexão superficial e infrutífera e ainda, sua experiência profissional não deve impedi-lo de buscar formação continuada. É natural que tenhamos conceitos distintos do que é ser um bom professor e que estas ideias sejam formadas a partir de suas próprias experiências, elas são aprimoradas e superadas sempre que as compartilhamos, trocamos ideias e ouvimos conselhos de outros educadores.

A postura correta do professor afeta o modo como os alunos reagem na sala de aula. Ele precisa ser seguro, dominante e justo, estabelecendo a sí próprio como figura de autoridade e modelo a ser seguido, mantendo o autocontrole e evitando reações exageradas quando desafiado. Outra postura equivocada é o professor tentar ser muito amigo do aluno - professor e aluno devem ter relações amigáveis e não relações de amizade - pois a hierarquia e autoridade precisam ser mantidas sem autoritarismo, respeitando e dignificando-os. GLASSER, 2000, sugeriu que "os professores adotem sete hábitos agregadores: cuidar, escutar, apoiar, contribuir, encorajar, confiar e mostrar-se amigável.

\section{Os motivos da indisciplina na perspectiva dos alunos}

Iniciamos este item explorando os conceitos de indisciplina apresentados pelos 
alunos através do questionário aplicado para três turmas do sétimo ano do ensino fundamental, em uma escola da área central da cidade de Londrina, no Paraná. O questionário aplicado procurou abordar questões que explicitassem suas opiniões e demonstrassem o quão grave acreditam ser os comportamentos que mais incomodam os docentes. Nossa pesquisa, inclui aspectos significativos do que os alunos trazem consigo das experiências com as situações de indisciplina na escola, o entendimento deles sobre o que é indisciplina, suas causas, os possíveis encaminhamentos, quem está envolvido, os significados e as intencionalidades que envolvem as expressões de indisciplina.

Foram entrevistados 33 alunos do sétimo ano do ensino fundamental, sendo $66 \%$ do sexo feminino, com idade entre 12 e 15 anos. Abordaremos cada um dos itens integrantes do questionário, citando inclusive as observações feitas pelos educandos em questões abertas.

Segundo eles, $75 \%$ dos pais demonstram ter muito interesse por sua vida escolar e $83 \%$ acreditam que a escola é um importante instrumento em sua vida. Quando perguntados sobre os tipos de aula que mais os motivam, entre as opções de aula expositiva, interativa, realização de trabalho em grupo e com recursos de multimídia, os resultados apontaram que 83\% escolheram a última como a melhor e ainda sugeriram aulas de campo e aulas ao ar livre como possíveis alternativas.

Ao questionarmos sobre a gravidade dos comportamentos mais observados em sala de aula, 58\% acreditaram ser pouco grave manter conversas paralelas com os colegas e trocar bilhetinhos durante as aulas (66\%), mas disseram ser muito grave comportamentos como não acatar as ordens do professor (91\%), não realizar tarefas (66\%) ou desrespeitar colegas (66\%) e professores (75\%). Já agredir fisicamente, interromper as aulas com questões ou atitudes pouco adequadas e sair de sala sem a autorização do professor é considerado pelos alunos algo gravíssimo (91\%, 83\% e 84\%, respectivamente).

Em relação às ocorrências de indisciplina, 58\% alegaram já ter recebido orientações devido ao mau comportamento, entretanto, $50 \%$ destes se consideram alunos disciplinados. Segundo eles, o desinteresse pela escola é o principal causador da indisciplina (67\%), seguido de aulas pouco interessantes (27\%) e castigos pouco severos para alunos indisciplinados (6\%). Alguns alunos citaram ainda que professores autoritários ou "muito bonzinhos" também podem ser causa deste 
problema. A maioria (58\%) julga adequadas as medidas tomadas pela escola para solucionar casos de indisciplina. Aqueles que discordaram, sugeriram envolver alunos em projetos, tornar o espaço escolar mais agradável, realizar um acompanhamento mais individualizado dos alunos com dificuldades, dialogar mais com os alunos e diversificar o tipo de aula como possíveis medidas a serem adotadas para resgatar os padrões disciplinares.

Foi conhecendo a perspectiva deste grupo de alunos sobre a indisciplina que percebemos os motivos e sentidos da indisciplina para eles. Através da análise dos dados da pesquisa pudemos constatar a legitimidade da indisciplina para os alunos. Eles, de fato, conseguem atribuir um motivo e um significado para as expressões de indisciplina. Quando relatam estas expressões, seja na sala de aula ou fora dela, os alunos expõem os motivos que os levam a agir daquela maneira. Percebemos também que os professores tendem a focalizar mais os alunos individualmente e não o grupo ou os subgrupos de alunos que estão presentes na sala de aula, agindo assim, tais professores ignoram as forças sociais que determinam o comportamento dos alunos.

É interessante perceber que a leitura que os alunos fizeram da indisciplina, na sala de aula e na escola, extrapola a leitura feita por seus professores. Para boa parte dos professores, dos alunos investigados por nós, a indisciplina estaria atrelada ao comportamento dos alunos. Portanto, tais professores tendem a relacionar a indisciplina mais as suas causas, sem atribuir-lhes sentidos.

\section{Gestão de sala de aula, algumas possibilidades}

Walters e Frei elencam algumas estratégias comprovadamente eficazes na gestão de sala de aula, abordaremos algumas delas de forma sucinta, a fim de facilitar o entendimento.

\section{Mantenha a voz calma}

Gritar tentando intimidar os alunos ou tentar falar em um tom de voz tão alto quanto o de uma turma inteira pode não ser uma boa tática pois, além de não facilitar a aprendizagem podem ter reações das mais diversas formas. Um boa dica é falar em um tom bem baixo, quase sussurrando, pois é da natureza humana que as crianças queiram saber o que está sendo dito em voz tão baixa. Como nem todos poderão ouvir 
da primeira vez, não espere que se acalmem, continue sussurrando, dando a eles algum tempo para que percebam e observe o que acontece.

\section{Contato visual}

Outro instrumento eficaz é o contato visual, desde que não sejam impróprios ou intimidem os alunos. Quando um aluno estiver se portando mal, pare e olhe-o nos olhos, - muitas vezes não é preciso dizer nada - não se trata de um gesto ameaçador, mas de um ato de autoridade. É importante olhar toda a classe e também levar em consideração a cultura de cada um, já que para algumas podem considerar grosseiro ou desrespeitoso o contato ocular direto.

\section{Elogios e correção}

Assim como professores, alunos também querem atenção e algumas vezes a forma que encontram de obtê-la é tendo comportamentos negativos. Entretanto, alunos corrigidos em público reagem se comportando pior pois estão respondendo (consciente ou inconsciente) à necessidade de obter atenção. Já o elogio deve ser sempre genuíno, merecido e promover a autoconfiança e autonomia na propensão a correr riscos na aprendizagem. A regra seria; corrija em particular e elogie em público.

\section{Escute antes de disciplinar}

Escutar os alunos é especialmente importante quando há uma situação na qual você não possui todas as informações pertinentes ou corretas. Quando o docente procede desta forma, demonstra respeito, irá ajudá-lo a tomar a decisão mais adequada e ainda será um momento de aprendizado para todos os envolvidos. É preciso manter a mente aberta para possíveis situações ou frustrações que talvez não estejam explicitas a principio.

\section{Dê instruções}

Mesmo parecendo algo simples, dar instruções de maneira afirmativa e em um tom de voz calmo e regular transmite ao aluno a mensagem de que ele é importante para você. Por exemplo: "Você é importante para esta discussão, precisamos que você preste atenção". Quando se deparar com um aluno que necessita constantemente de instruções, olhe-o nos olhos, chame-o pelo nome, aproxime-se 
bem dele e de sugestões verbais e não verbais apropriadas. Depois de dar as instruções, dê um tempo para que processe a instrução, decida obedecer e de fato obedeça, durante esse intervalo não converse nem discuta, apenas o olhe e se necessário, faça novamente a solicitação.

\section{Evite confrontos com os alunos}

Como professor, você já é autoridade e por este motivo não há a necessidade de discutir. Além de inúteis, estes confrontos desgastam a imagem do professor. Alunos que discordam do que o professor exige devem ser estimulados a discutir as questões e particular e não se deve permitir que discutam ou desafiem o professor publicamente. Se houver insistência mesmo depois de receber a instrução, simplesmente diga: "Mesmo assim..." e dê novamente sua instrução.

\section{Elimine o uso de ameaças}

Ameaçar alunos pode levar à obediência temporária mas não os ajudará a tomar decisões éticas e ponderadas sobre seu comportamento futuro. Explicar claramente as consequências negativas e positivas de suas escolhas e se mesmo assim o aluno optar por ter comportamento negativo, terá consciência destas consequências geradas por sua opção. Mas é preciso estar preparado para sustentar o que disse, do contrario é melhor não dizer nada do que correr o risco de dizer algo que não possa ser praticado.

\section{CONCLUSÃO}

Devido ao caráter complexo envolvido nas questões de indisciplina escolar, ainda há muito a ser feito em nosso país no que diz respeito a pesquisas científicas. Ao buscar publicações nacionais relacionadas a este assunto, percebe-se um número muito limitado e certamente muito abaixo do considerado necessário para embasar encaminhamentos, reflexões, planos de ação e outras formas de enfrentamento das questões relacionadas com a indisciplina escolar baseados na realidade das escolas brasileiras. Esta área fértil para pesquisas, poderia por exemplo, investigar junto aos alunos possíveis relações a indisciplina e as práticas escolares que Ihes causam descontentamento, sentimentos como tédio, necessidade de atenção, de poder ou 
vingança - sentimentos comuns a todos os seres humanos - podem desencadear situações de indisciplina. Outro ponto destacado pelos autores são as possíveis relações entre a indisciplina e rotinas ou metas não estabelecidas previamente e como ela interfere no currículo praticado.

É preciso ter clareza de que não se trata apenas de evidenciar o comportamento dos alunos e sim focalizar os aspectos relacionados ao desenvolvimento social e psicológico e cognitivo podem ser relacionados as práticas educativas das escolas, assim, o fato de o aluno não acompanhar o ritmo de estudos da classe e consequentemente não aprender, pode culminar em situações de indisciplina. A formação continuada de professores com discussões relacionadas a este assunto e o compartilhamento com os colegas de experiências de sucesso em gestão de sala de aula, podem ser alternativas a curto e médio prazo para auxiliar os profissionais a encontrar saídas para este assunto tão discutido, entretanto tão pouco pesquisado em nosso país.

Podemos afirmar que a perspectiva dos alunos sobre a indisciplina pode auxiliar no entendimento de seus motivos e indicar possíveis elementos para fundamentar formas de condução pedagógica do trabalho docente, fornecendo elementos para que professores ampliem sua percepção das questões relacionadas a este tema. Outro fator importante é perceber o quanto os alunos são capazes de perceber fragilidades nas práticas pedagógicas, o que leva o educador a buscar a compreensão dos motivos da indisciplina em suas aulas, aprendendo a reconhecer as necessidades que suas expressões podem estar comunicando.

Por fim, entendendo que a indisciplina hoje representa um dos principais desafios da educação atual, concordamos com Garcia (1999) quando afirma que mais que transformar nossas escolas, precisamos reinventá-las.

\section{REFERÊNCIAS}

GARCIA, J. Indisciplina na escola. Rev. Paranaense Desenvol., n.95, p.101-108, 1999.

GARCIA, J. A construção social da indisciplina na escola. In: SEMINÁRIO INDISCIPLINA NA EDỦCAÇÃO CONTEMPORÂNEA, 1, 2005. Curitiba. Anais... Curitiba: UTP, 2005, p. 87-93.

GLASSER, W. Every student can succed. San Diego, CA. Black Forrest, 2000.

GOLBA, M. Os motivos da indisciplina na escola: a perspectiva dos alunos. In: CONGRESSO NACIONAL DE EDUCAÇÃO - EDUCERE, III Encontro Sul Brasileiro 
de Psicopedagogia, 2009, Curitiba. Anais... Curitiba: PUC, 2009. p. 9832-9842.

MARSHALL, M. Curriculum, isntruction, clasroom menagment, and discipline. Disponível em: <http://www.teachers.net/gazette/FEB03/marshall.htm/ >. Acesso em: 20 jul. 2015.

TARDIF, M. Saberes docente e formação profissional. Petrópolis: Vozes, 2002.

WALTERS, J.; FREI, S. Gestão do comportamento e da disciplina em sala de aula. São Paulo: Special Book Services Livraria, 2009.

WONG, H.K.; WONG, R.T. The first days of school: How to be an effective teacher. Mountain View: Harry K. Wong, 1998.

\section{APÊNDICES}

\section{A. Identificação}

Questionário sobre (in)disciplina elaborado para os alunos do $7^{\circ} \mathrm{e} 8^{\circ}$ ano

1- Sexo ( ) Feminino

2- Idade ( ) 10 a 12 anos

3- Série ( ) $6^{\circ}$ ano

\section{B. Atitude perante a escola}

( ) Masculino

4 - Qual a importância da escola na sua vida?

( ) Muito importante ( ) Importante ( ) Pouco importante ( ) Nada importante

5- Indique o grau de interesse dos seus pais pela sua vida escolar?

\begin{tabular}{|c|c|c|c|c|}
\hline $\mathbf{1}$ & $\mathbf{2}$ & $\mathbf{3}$ & $\mathbf{4}$ & $\mathbf{5}$ \\
\hline & & & & \\
\hline
\end{tabular}

6 - Como você classificaria o ambiente da sua sala de aula?

\begin{tabular}{|c|c|c|c|c|}
\hline $\mathbf{1}$ & $\mathbf{2}$ & $\mathbf{3}$ & $\mathbf{4}$ & $\mathbf{5}$ \\
\hline & & & & \\
\hline
\end{tabular}

7 - Quais são os tipos de aula que mais te motivam? (Pode escolher várias opções)

( ) aula expositiva

) aula interativa

) realização de trabalho em grupo

) com recursos de multimídia (Tv, Som, Computador, Projetor)

) Outra:

8 - Indique o grau de gravidade dos seguintes comportamentos:

Marque com 1 ao 5: 1 - Pouco grave e 5 - Muito grave

( ) Manter conversas paralelas com os colegas

( ) Trocar mensagens e papelinhos

) Não acatar as ordens dos professores

) Não realizar as tarefas da aula

) Faltar ao respeito aos colegas

) Faltar ao respeito aos professores

) Agredir fisicamente os colegas

) Agredir fisicamente os professores

) Interromper as aulas com questões ou atitudes pouco adequadas

) Sair da aula sem autorização

9 - Você já teve alguma ocorrência de indisciplina na sua vida escolar?

( ) Sim

10- Se sim, indique a frequência

11 - Você se considera um aluno:

1

) Poucas

( ) Muitas

2

3

4 
C - Medidas para melhorar a disciplina na escola

12. Qual a principal causa de indisciplina na sua escola?

( ) Espaços escolares pouco vigiados

( ) Castigos poucos severos para os alunos indisciplinados

( ) Problemas familiares

( ) Desinteresse pela escola

( ) Aulas pouco interessantes

( ) Outra:

13- Você acha que as medidas adotadas pela escola para resolver casos de indisciplina são adequadas?

) $\operatorname{Sim} \quad(\quad$ ) Não

14 - Se respondeu NÃO, que outras medidas sugere? (Pode escolher mais do que uma opção.)

( ) Dialogar mais com os alunos

( ) Diversificar o tipo de aula

( ) Responsabilizar toda a turma pelo comportamento individual

( ) Manter os pais/responsáveis bem informados sobre o comportamento do aluno.

( ) Envolver os alunos em projetos

( ) Tornar o espaço escolar mais agradável

( ) Acompanhamento mais individualizado dos alunos com dificuldades

( ) Outra:

15 - Qual o ambiente escolar mais te agradaria?

( ) Descontraído, em que os professores pudessem ser abordados pelos alunos sem grande formalidade;

( ) Formal, em que toda e qualquer atividade estivesse devidamente enquadrada num horário bem definido;

( ) Misto em que as atividades (propostas não só pela escola como pelos alunos) estejam bem programadas no calendário. 